\title{
Total effective time of the forced expirogram in disease: sources of error and a correction factor
}

\author{
J JORDANOGLOU, C HADJISTAVROU, G TATSIS, E ANEVLAVIS, \\ C MELISSINOS
}

\begin{abstract}
From the Department of Pulmonary Diseases, University of Athens Medical School, Sotiria Hospital, Athens, Greece
\end{abstract}

ABSTRACT Effective time of the forced expirogram is a sensitive index for the detection of mild airways obstruction. However, there is evidence that this measurement is not superior to maximum

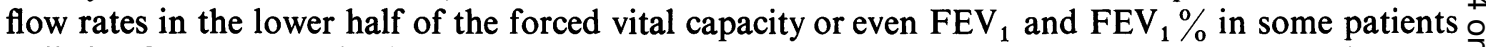
suffering from obstructive lung disease. Furthermore we noticed that in some patients with a decrease $\rightarrow$ of the forced vital capacity caused by exacerbation of airways obstruction, the effective time was not $\rightarrow$ appreciably changed. We concluded that this apparent diasdvantage of the effective time is the result of the different forced vital capacities. To eliminate this error we transformed the forced expirogram $\vec{\emptyset}$ to the equivalent curve that the patient would produce, if his forced vital capacity was equal to the predicted mean value for his age, sex, and height. The derived corrected total effective time seems to 0 have increased sensitivity for detection of small changes in expirograms obtained from the same subject or from different subjects.

It has been shown that the total effective time $\left(\right.$ teff $\left._{T}\right)$ or its equal mean transit time (MTT) of the forced expiratory spirogram (FVC-t curve) is a sensitive parameter for the detection of upper and lower airways obstruction. ${ }^{1-4}$ However, we noticed that in patients with obstructive lung disease the total effective time was not so long as expected. Bello et $a l^{5}$ found that bronchodilatation was better assessed with $F E V_{1}$ and $\dot{V}_{50}$ than with MTT and the other moments. Osmanliev et $a l^{6}$ found that MTT was no better than $\dot{V}_{50}, \dot{V}_{25}$ in separating smokers from non-smokers. Moreover, Liang et al ${ }^{7}$ noticed that MTT was not more sensitive than MMEF, $\dot{\mathrm{V}}_{25}, \dot{\mathrm{V}}_{50}, \mathrm{FEV}_{1} \%$ in detecting change after inhalation of salbutamol aerosol. These findings represent a considerable disadvantage of this parameter $\left(\operatorname{teff}_{\mathrm{T}}\right.$, MTT) in the assessment of airways obstruction.

\section{Methods}

We studied 25 patients, of whom seven had chronic bronchitis, eight bronchial asthma, one tracheal stenosis caused by carcinoma, and nine lung fibrosis. The diagnosis of the disease was made on clinical and radiological grounds. The functional abnormality was assessed mainly by simple spiro-

Address for reprint requests: Dr J Jordanoglou, Department of Pulmonary Diseases, University of Athens Medical School, Sotiria Hospital, Athens, Greece.

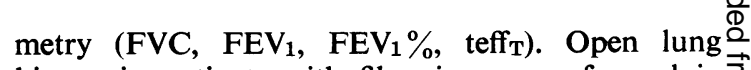
biopsy in patients with fibrosis was performed in $\overrightarrow{\overrightarrow{0}}$ five patients and skin biopsy in one. Bronchoscopy 3 was performed in the patient with tracheal stenosis.

The lung function tests were performed in most of the patients before and on several occasions during treatment. The patient in the sitting position expired maximally from total lung capacity (TLC) to residual ${ }_{0}^{\times}$ volume (RV) through a mouthpiece (id $2.55 \mathrm{~cm}$ ) into 3 a water spirometer. The speed of the paper was $20 \%$ $\mathrm{mm} / \mathrm{s}$.

Great care was taken to ensure that the patient expired as forcibly as possible and until no further? air could be expelled. Three maximal expirograms $\frac{}{2}$ were recorded with a time interval of five minutes between the expiratory manoeuvres. The curve with $N$ the maximum FVC was selected for the calculation of FVC, FEV, $\mathrm{FEV}_{1} \%$, and effective time (teff) 공 Effective time was calculated in the complete ex- $\omega$ pirogram (total effective time, teff $\mathrm{T}_{\mathrm{T}}$ ) and in the park of the curve corresponding to the time interval of six seconds (teff ${ }_{6}$ ). We also calculated the corrected total effective time (teff ${ }_{\mathrm{TC}}$ ), using the equation.

(see Appendix)

$$
\text { teff }_{\mathrm{TC}}=\operatorname{teff}_{\mathrm{T}} / \frac{\mathrm{FVC}}{\mathrm{FVCN}}
$$

(Where: FVC = actual value of the patient's FVC and $\mathrm{FVCN}=$ predicted normal value of the FVE for the patient.) ${ }^{8}$ 
Table 1 Measurements from five patients in whom FVC/predicted FVC was $\geqslant 1$. Numbers in brackets indicate the normal range for the ratios

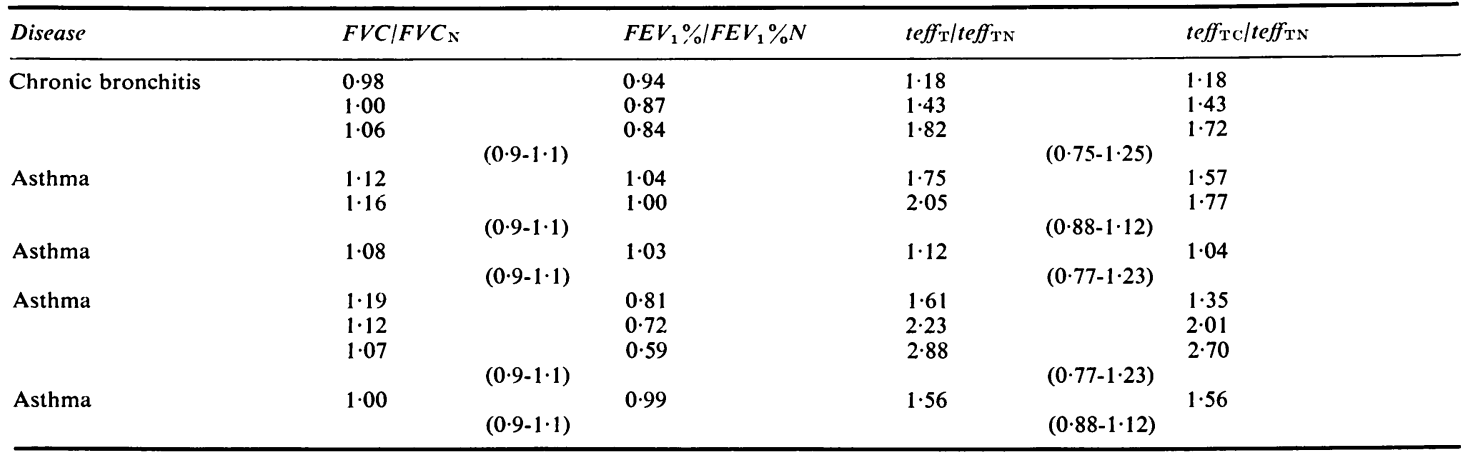

Table 2 Measurements from five patients with long teff $\mathrm{TC}_{\mathrm{C}}$ and normal teff $\mathrm{T}$. Numbers in brackets indicate the normal range for the ratios

\begin{tabular}{|c|c|c|c|c|c|c|}
\hline Disease & $F V C / F V C_{\mathrm{N}}$ & & $F E V_{1} \% / F E V_{1} \% N$ & teff $_{\mathrm{T}} /$ teff $_{\mathrm{TN}}$ & & $t_{e f f} \mathrm{TC} /$ teff $_{\mathrm{TN}}$ \\
\hline Chronic bronchitis & 0.68 & $(0 \cdot 9-1 \cdot 1)$ & 0.96 & 1.07 & $(0 \cdot 75-1 \cdot 25)$ & 1.58 \\
\hline Fibrosis & $\begin{array}{l}0.63 \\
0.76\end{array}$ & $(0 \cdot 9-1 \cdot 1)$ & $\begin{array}{l}1.03 \\
1.09\end{array}$ & $\begin{array}{l}0.90 \\
1 \cdot 10\end{array}$ & $(0.88-1 \cdot 12)$ & $\begin{array}{l}1.42 \\
1.44\end{array}$ \\
\hline Fibrosis & 0.54 & $(0 \cdot 9-1 \cdot 1)$ & $1 \cdot 12$ & $0 \cdot 84$ & $(0 \cdot 75-1 \cdot 25)$ & $1 \cdot 58$ \\
\hline Fibrosis & 0.51 & $(0 \cdot 9-1 \cdot 1)$ & 1.05 & 0.75 & $(0.75-1.25)$ & 1.48 \\
\hline Fibrosis & 0.71 & $(0 \cdot 9-1 \cdot 1)$ & 1.02 & 0.91 & $(0 \cdot 88-1 \cdot 12)$ & $1 \cdot 30$ \\
\hline
\end{tabular}

\section{Results}

Seventy maximal expirograms obtained from 25 patients were studied. The results are expressed as the ratio of the patient's value for teff ${ }_{\mathrm{T}}$, teff $\mathrm{TC}_{\mathrm{T}}$, $F V C$ and $F E V_{1} \%$ over the corresponding predicted mean value. In all the patients teff ${ }_{\mathrm{TC}}$ was longer than teff $\mathrm{T}$, except in 10 curves from five obstructive patients in which the ratio $\mathrm{FVC} / \mathrm{FVCN}$ was greater than or equal to unity (table 1). In six curves from five patients teff ${ }_{\mathrm{TC}}$ was abnormally long while teff ${ }_{\mathrm{T}}$ was normal (table 2). In 21 curves from nine patients suffering from airways obstruction and fibrosis worsening of the clinical condition was associated with no change or even shortening of teff ${ }_{T}$ while teff ${ }_{\mathrm{TC}}$ was becoming longer (table 3 ).

The reduction of the $\mathrm{FEV}_{1} \%$ ratio was followed by the elongation of teff ${ }_{\mathrm{TC}}$. However in 33 expirograms from 15 patients suffering from airways obstruction and fibrosis deterioration of the clinical condition was associated with a small change $(<5 \%)$ (decrease or even an increase) of the $\mathrm{FEV}_{1} \%$ ratio while teff ${ }_{T C}$ was becoming longer (table 4). In these patients the teff $f_{T}$ did not always follow the change of teff ${ }_{\mathrm{TC}}$. The effective time measured at the time interval of six seconds (teff 6 ) was compared to the total effective time (teff ${ }_{T}$ ) in 38 expirograms from 16 patients suffering from chronic bronchitis and
Table 3 Measurements from nine patients in whom teff ${ }_{\mathrm{TC}}$ lengthened but teff $f_{\mathrm{T}}$ did not when condition deteriorated. Numbers in brackets indicate the normal range for the ratios. Worsening of the clinical condition is according to the direction from above downwards for each patient

\begin{tabular}{|c|c|c|c|}
\hline Disease & $F V C / F V C_{\mathrm{N}}$ & $t_{e f f} / t e f f_{\mathrm{TN}}$ & $t_{e f f} T_{T} / t_{e f f} T_{N}$ \\
\hline Chronic bronchitis & $\begin{array}{l}0 \cdot 95 \\
0 \cdot 79 \\
(0 \cdot 9-1 \cdot 1)\end{array}$ & $\begin{array}{l}1.98 \\
1.74\end{array}$ & $\begin{array}{l}2 \cdot 08 \\
2 \cdot 20 \\
23)\end{array}$ \\
\hline Chronic bronchitis & $\begin{array}{l}0.51 \\
0.45 \\
0 \cdot 38 \\
(0 \cdot 9-1 \cdot 1)\end{array}$ & $\begin{array}{l}2 \cdot 17 \\
2 \cdot 15 \\
2 \cdot 17\end{array}$ & $\begin{array}{r}4 \cdot 28 \\
4 \cdot 82 \\
5 \cdot 79 \\
23)\end{array}$ \\
\hline Tracheal stenosis & $\begin{array}{l}0 \cdot 75 \\
0 \cdot 75 \\
0 \cdot 30 \\
(0 \cdot 9-1 \cdot 1)\end{array}$ & $\begin{array}{l}2 \cdot 59 \\
3 \cdot 26 \\
1 \cdot 71\end{array}$ & $\begin{array}{r}3 \cdot 47 \\
4 \cdot 38 \\
5 \cdot 59 \\
25)\end{array}$ \\
\hline Asthma & $\begin{array}{l}0.96 \\
0.92 \\
0.60 \\
(0 \cdot 9-1 \cdot 1)\end{array}$ & $\begin{array}{l}1.67 \\
1.62 \\
1.47\end{array}$ & $\begin{array}{r}1.74 \\
1.77 \\
2 \cdot 46 \\
23)\end{array}$ \\
\hline Asthma & $\begin{array}{l}1 \cdot 12 \\
0 \cdot 38 \\
(0 \cdot 9-1 \cdot 1)\end{array}$ & $\begin{array}{l}1.75 \\
1.30\end{array}$ & $\begin{array}{r}1 \cdot 57 \\
3 \cdot 44 \\
12)\end{array}$ \\
\hline Asthma & $\begin{array}{l}1 \cdot 07 \\
0 \cdot 60 \\
(0 \cdot 9-1 \cdot 1)\end{array}$ & $\begin{array}{l}2 \cdot 88 \\
2 \cdot 16\end{array}$ & $\begin{array}{r}2 \cdot 70 \\
3.59 \\
23)\end{array}$ \\
\hline Asthma & $\begin{array}{l}0.57 \\
0.47 \\
(0 \cdot 9-1 \cdot 1)\end{array}$ & $\begin{array}{l}3.47 \\
3 \cdot 34\end{array}$ & $\begin{array}{r}6.09 \\
7 \cdot 09 \\
25)\end{array}$ \\
\hline Asthma & $\begin{array}{l}0.87 \\
0.72 \\
(0 \cdot 9-1 \cdot 1)\end{array}$ & $\begin{array}{l}2 \cdot 60 \\
2 \cdot 60\end{array}$ & $(0 \cdot 75-1 \cdot 25)^{3 \cdot 58}$ \\
\hline Fibrosis & $\begin{array}{l}0.64 \\
0.45 \\
(0 \cdot 9-1 \cdot 1)\end{array}$ & $\begin{array}{l}0.30 \\
0.30\end{array}$ & $\begin{array}{l}0.47 \\
0.67 \\
25)\end{array}$ \\
\hline
\end{tabular}


Table 4 Measurements from 15 patients in whom teff $_{\mathrm{Tc}}$ lengthened but FEV $\%$ /predicted FEV $\%$ changed little when condition worsened. Clinical deterioration is from above downwards for each patient

\begin{tabular}{|c|c|c|c|}
\hline \multirow{3}{*}{$\frac{\text { Disease }}{\text { Chronic bronchitis }}$} & \multirow{3}{*}{$\begin{array}{l}F V C / F V C \mathrm{~N} \\
0.60 \\
0.62\end{array}$} & \multicolumn{2}{|c|}{$F E V_{1} \% / F E V_{1} \% N$ teff ${ }_{\mathrm{Tc}} /$ teff $_{\mathrm{TN}}$} \\
\hline & & 0.74 & $3 \cdot 32$ \\
\hline & & 0.73 & $3 \cdot 56$ \\
\hline \multirow[t]{2}{*}{ Chronic bronchitis } & 0.95 & $0 \cdot 76$ & $2 \cdot 08$ \\
\hline & $0 \cdot 79$ & 0.82 & $2 \cdot 20$ \\
\hline \multirow[t]{2}{*}{ Chronic bronchitis } & $0 \cdot 72$ & $0 \cdot 71$ & 1.95 \\
\hline & 0.72 & $0 \cdot 72$ & $2 \cdot 68$ \\
\hline \multirow[t]{2}{*}{ Chronic bronchitis } & $1 \cdot 00$ & $0 \cdot 87$ & 1.43 \\
\hline & 1.06 & 0.84 & $1 \cdot 72$ \\
\hline \multirow[t]{2}{*}{ Chronic bronchitis } & $0 \cdot 32$ & 0.46 & $8 \cdot 41$ \\
\hline & 0.42 & 0.41 & $8 \cdot 79$ \\
\hline \multirow[t]{3}{*}{ Chronic bronchitis } & 0.51 & 0.66 & $4 \cdot 28$ \\
\hline & 0.45 & 0.66 & $4 \cdot 82$ \\
\hline & $0 \cdot 38$ & 0.66 & $5 \cdot 79$ \\
\hline \multirow[t]{3}{*}{ Tracheal stenosis } & $0 \cdot 75$ & 0.55 & $3 \cdot 47$ \\
\hline & $0 \cdot 75$ & $0 \cdot 50$ & $4 \cdot 38$ \\
\hline & $0 \cdot 30$ & 0.65 & $5 \cdot 59$ \\
\hline \multirow[t]{2}{*}{ Asthma } & 0.92 & 0.92 & $1 \cdot 77$ \\
\hline & 0.60 & 0.94 & $2 \cdot 46$ \\
\hline \multirow[t]{2}{*}{ Asthma } & $1 \cdot 12$ & $1 \cdot 04$ & $1 \cdot 57$ \\
\hline & $1 \cdot 16$ & 1.00 & $1 \cdot 77$ \\
\hline \multirow[t]{3}{*}{ Asthma } & 0.96 & 0.95 & $1 \cdot 35$ \\
\hline & 0.95 & 0.94 & $1 \cdot 50$ \\
\hline & 0.91 & 0.95 & $1 \cdot 70$ \\
\hline \multirow[t]{2}{*}{ Asthma } & 1.07 & 0.59 & $2 \cdot 70$ \\
\hline & 0.60 & 0.60 & $3 \cdot 59$ \\
\hline \multirow[t]{2}{*}{ Asthma } & 0.80 & 0.75 & 3.46 \\
\hline & 0.72 & 0.77 & 3.58 \\
\hline \multirow[t]{2}{*}{ Asthma } & 0.93 & 0.99 & $1 \cdot 36$ \\
\hline & $1 \cdot 00$ & 0.99 & $1 \cdot 56$ \\
\hline \multirow[t]{2}{*}{ Fibrosis } & $0 \cdot 76$ & 1.09 & $1 \cdot 44$ \\
\hline & 0.69 & 1.06 & $1 \cdot 78$ \\
\hline \multirow[t]{2}{*}{ Fibrosis } & 0.64 & $1 \cdot 35$ & 0.54 \\
\hline & 0.45 & $1 \cdot 38$ & 0.67 \\
\hline
\end{tabular}

bronchial asthma. Eleven of these patients in 22 expirograms showed teff $_{6}$ definitely shorter than teff ${ }_{\mathrm{T}}$.

\section{Discussion}

Total effective time $\left(\operatorname{teff}_{T}\right)$ was originally developed from a single exponential volume-time curve and then applied to multiple exponential curves. ${ }^{4}$ The ratio of the area $\left(\int \mathrm{Vdt}\right)$ to the volume change (V) was called effective time (teff) because it was shown in volume-time curves, mainly inspiratory, during spontaneous breathing, that the ratio $\mathrm{V} / 2$ teff was equal to the effective value of flow (root mean square flow) (unpublished data). Mean transit time of the maximal expirogram (MTT) is the first statistical moment of the curve. ${ }^{1-39-11}$ These two terms (teff, MTT) have the same value if measured at the same time interval on the expirogram.

In normal young subjects as well as in patients suffering from fibrosis there is no difference between teff $T_{T}$ and teff ${ }_{6}$ because forced expiratory time (FET) is shorter than six seconds. However, in patients with airways obstruction, in whom FET is longer than six seconds, teff $\mathrm{T}_{\mathrm{T}}$ is longer than teff 6 . According to the above, the six seconds time interval used for $\overrightarrow{\vec{s}}$ the calculation of teff 6 reduces the sensitivity of this $\frac{7}{0}$ parameter. It may be argued that the duration of the $\frac{\mathrm{C}}{\mathrm{O}}$ FVC is as arbitrary as using a fixed interval, say of $\frac{\bar{m}}{\frac{1}{}}$ six seconds. The whole FVC-t curve is the result of $\vec{\Phi}$ the maximum effort of the patient and the duration 0 time of three consecutive expirograms may be $\mathrm{s}$ different. The maximum value of the FVC in one of $\overrightarrow{0}$ these expirograms does not necessarily imply that $\overrightarrow{\vec{A}}$ its forced expiratory time will also be the maximal. $\vec{\sigma}$ Small changes in FET in consecutive expirograms from the same subject do not affect materially the $x$ magnitude of the effective time (unpublished data). W

It has been suggested that mathematical extra- $\vec{\omega}$ polation to infinity of the FVC-t curve would avoid ${ }^{\omega}$ the difficulty in selecting the end-point for the calculation of teff. This method could be applied if the maximal expirogram followed a certain mathematical $\vec{D}$ expression. We have found that the majority of the expirograms are multiple exponential curves (unpublished data). So the extrapolation curve to in- $\oplus$ finity between the point of the patient's RV and that $\mathrm{N}$ of the patient's normal value of RV cannot be predicted.

It has been noticed in some patients with a considerable decrease in FVC that the total effective time is normal or deviates slightly from normality $\stackrel{\varnothing}{\unrhd}$ while other parameters $\left(\mathrm{FVC}, \mathrm{FEV}_{1}, \mathrm{FEV}_{1} \%\right.$ ) and $\overrightarrow{\vec{F}}$ the clinical findings indicate airways obstruction. In $\frac{O}{3}$ order to overcome this apparent disadvantage of $\bar{\partial}$ teff $_{T}$ we transformed the actual FVC-t curve to the equivalent curve that the patient with the same mechanical condition of the "lung-chest wall" would o produce if his FVC was equal to the predicted mean $\underset{\sim}{\otimes}$ value for his age, sex and height. The transformation $\frac{\dot{\sigma}}{3}$ of the FVC-t curve to the equivalent curve is based on the following concept: two maximal expirograms 8 with different FVC are compared to each other in $₹$ terms of volume change at several preselected time 의 intervals which are the same for both expirograms. It is evident that, when the comparison is to be made in terms of time, the preselected volumes must also $N$ be the same. The actual FVC-t curve and its equiva- $\sigma$ lent curve have the same mean flow (see Appendix). $\mathcal{O}$ By using this concept we actually compare in terms $\underset{\omega}{N}$ of time the equivalent FVC-t curves of patients with the same predicted normal FVC values. The trans- 0 formation of the actual FVC-t curve was achieved by $\stackrel{\overparen{D}}{\overparen{D}}$ dividing the coordinates of each point along the $\stackrel{\oplus}{+}$ curve by the factor FVC/FVCN. The effective time of the equivalent curve was called corrected total effective time (teff $\mathrm{TC}_{\mathrm{TC}}$ ) (Appendix). In this way it was $\stackrel{\mathbb{D}}{\square}$ possible to relate properly to each other, in terms of $\mathbb{Q}$ effective time, expirograms with different vital capacities obtained from the same subject or from different subjects with the same predicted normal 
FVC values. There may be an argument that in the case of lung resection the corrected total effective time will give an incorrect image of the situation. The total effective time of the expirogram obtained from a normal subject is the same as that obtained from one lung only and each lung has the same teff $T$ as that of the contralateral lung (unpublished data). In a patient with one lung excised and the other lung normal teff $\mathrm{T}_{\mathrm{T}}$ is normal while teff $\mathrm{TC}_{\mathrm{TC}}$ is nearly doubled because $\mathrm{FVC} / \mathrm{FVCN} \simeq 0.5$. In this particular case the ratio $F V C N / 2$ teff $_{\mathrm{TC}}$ is equal to $\mathrm{FVC} / 2$ teff $_{\mathrm{T}}$, which is nearly the same with the mean flow $\left(\Sigma_{\text {to }}^{\mathrm{t}} \dot{\mathrm{V}} / \mathrm{t}\right)$ obtained from a flow-time curve. The differential diagnosis of prolonged teff $\mathrm{TC}_{\mathrm{TC}}$ between excised lung and airways obstruction can be made by using the static lung capacity TLC and the ratio RV/TLC. Patients with chronic bronchitis or bronchial asthma during treatment showed no appreciable further change in FVC, FEV $1, \mathrm{FEV}_{1} \%$ and teff ${ }_{T}$ while teff ${ }_{\mathrm{TC}}$ was improving. This is the result of a small increase in FVC; decrease in teff $\mathrm{T}_{\mathrm{T}}$, which alone is not of any practical importance, resulted in a definite reduction of teff $\mathrm{Tc}_{\mathrm{T}}$. This may be of particular interest in clinical medicine as it implies that, even if maximum improvement of the parameters FVC, $\mathrm{FEV}_{1}, \mathrm{FEV}_{1} \%$, and teff $\mathrm{T}_{\mathrm{T}}$ is achieved, treatment has to be continued until teff ${ }_{\mathrm{TC}}$ can be shortened no further. The fact that FVC, FEV $\mathrm{FEV}_{1} \%$, and/or teff $\mathrm{T}_{\mathrm{T}}$ remain practically stable while teff $\mathrm{TC}_{\mathrm{T}}$ improves may be considered as evidence that this is a sensitive method for assessing the mechanical performance of the "chest wall-lung" system.

\section{References}

${ }^{1}$ Fish J, Menkes H, Rosenthal R, Summer W, Norman P, Permutt S. The effect of acute bronchospasm on the distribution of transit times during forced expiration. Am Rev Respir Dis 1974;109:700.

${ }^{2}$ Neuburger N, Levison H, Bryan AC, Kruger K. Transit time analysis of the forced expiratory spirogram in growth. J Appl Physiol 1976;40:329-32.

${ }^{3}$ Neuburger N, Levison $\mathbf{H}$, Kruger $\mathrm{K}$. Transit time analysis of the forced expiratory vital capacity in cystic fibrosis. Am Rev Respir Dis 1976;114:753-9.

4 Jordanoglou J, Koursouba R, Lalenis C, Gotsis T, Kontos $\mathrm{J}$, Gardikas C. Effective time of the forced expiratory spirogram in health and airways obstruction. Thorax 1979;34:187-93.

${ }^{5}$ Bello R, Campbell MJ, Collins G, Cotes JE, Tagaro DR. Transit time and derivatives as guides to the reversibility of chronic airflow obstruction. Thorax 1980;35:225.

${ }^{6}$ Osmanliev DP, Davies EE, Pride NB. Transit time analysis of the forced expiratory spirogram in male smokers. Thorax $1980 ; 35: 224-5$.

${ }^{7}$ Liang A, Macfie AE, Harris EA, Whitlock RML. Transit time analysis of the forced expiratory spirogram during clinical remission in juvenile asthma. Thorax 1979;34: 194-9.

${ }^{8}$ Cotes JE. Lung function, assessment and application in medicine. Second edition. Oxford: Blackwell, 1968.

${ }^{9}$ Tockman M, Menkes $\mathrm{H}$, Cohen B et al. A comparison of pulmonary function in male smokers and nonsmokers. Am Rev Respir Dis 1976;114:711-22.

${ }^{10}$ Permutt S, Menkes HA. Spirometry: analysis of forced expiration within the time domain. In: Macklem P, Permutt $\mathrm{S}$, eds. The lung in the transition between health and disease. New York: Marcel Dekker, 1979.

${ }^{11}$ Pride NB. Analysis of the forced expiration-a return to the recording spirometer? Thorax 1979;34:144-7.

\section{Appendix}

The mechanical behaviour of the "chest wall-lung" system is reflected in the morphology of the maximal expirogram. The curvature of the FVC-t curve, at any point along it, expresses the relationship between volume change and time, ie, the instantaneous flow, and it can be defined by its coordinates on the volume and time axes. By dividing each of these coordinates by the ratio FVC/FVCN the real FVC-t curve is extended to the equivalent curve without changing the value of the instantaneous flow at that point (figure). So the patient's expirogram is transformed to the equivalent curve with FVC equal to the predicted normal mean value for his age, sex and height and in which the mean expiratory flow ( $\mathrm{FVCN} / 2$ teff $\mathrm{TC}$ ) is equal to that of the real curve $\left(\mathrm{FVC} / 2\right.$ teff $\left._{\mathrm{T}}\right)$. The relationship between teff $\mathrm{T}, \mathrm{FVC} /$ FVCN and teff $\mathrm{TC}_{\mathrm{C}}$ is given by the equation.

$$
\text { teff }_{\mathrm{TC}}=\operatorname{teff}_{\mathrm{T}} / \frac{\mathrm{FVC}}{\mathrm{FVCN}}
$$

In the figure the real maximal expirogram of an obstructive patient (.-.-.) is transformed to the equivalent curve (o-o-o) by dividing each of the volume and time coordinates at any point along the real curve by the ratio $F V C / F V C N$. The angles $a$ and $b$ are equal to each other and their tangent represents the mean expiratory flow.

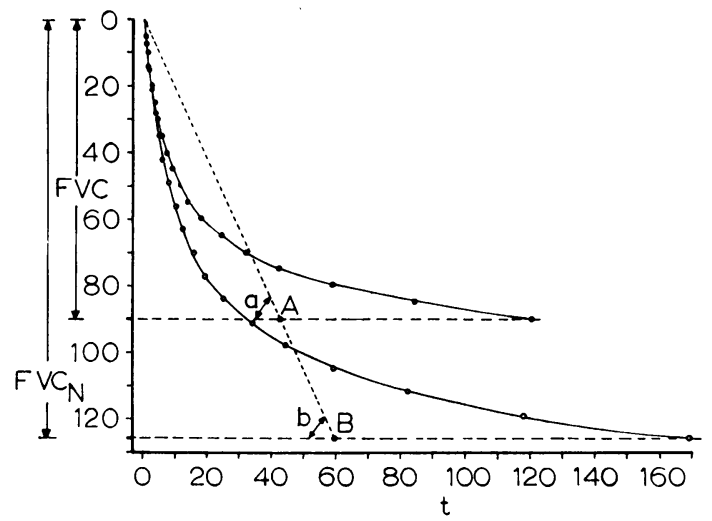

Figure Real maximal expirogram (above) of an obstructive patient and the equivalent curve (below). The equivalent curve is calculated by dividing the coordinates of each point on the real expirogram by the factor $F V C / F V C \mathrm{~N}$. The ratio of the area $\int V d t$ of the equivalent curve over FVCN is the corrected total effective time (teff $\left.f_{\mathrm{Tc}}\right)$. The relationship between teff $\mathrm{TC}_{\mathrm{TC}}$ 
teff $_{\mathrm{T}}$ and $F V C / F V C \mathrm{~N}$ is given by the equation

$$
t_{e f f} \mathrm{TC}_{\mathrm{C}}=\operatorname{teff}_{\mathrm{T}} / \frac{F V C}{F V C_{\mathrm{N}}}
$$

The point $A$ corresponds to 2 teff $_{\mathrm{T}}$ of the real curve and point $B$ to 2 teff $_{\mathrm{Tc}}$ of the equivalent curve. Angle a is equal to angle $b$ and the tangent of these angles is the mean expiratory flow which is the same in both curves- ie, $F V C / 2$ teff $_{\mathrm{T}}=F V C \mathrm{~N} / 2$ teff Tc. $F V C$ is the real forced vital capacity of the patient and $F V C_{\mathrm{N}}$ is the predicted normal value for his age, height, and sex. Zero point on volume axis corresponds to the level of $T L C$. Volume and time axis in millimetres $(1 \mathrm{~mm}=0.03 \mathrm{l}$, $1 \mathrm{~mm}=0.05 \mathrm{~s})$. In this example, FVC/FVCN $=0.715$, teff $\mathrm{T}=1.066 \mathrm{~s}$ (predicted: $1.121 \mathrm{~s})$, teff $_{\mathrm{TC}}=1.491 \mathrm{~s}$, $F V C / 2$ teff $_{\mathrm{T}}=F V C \mathrm{~N} / 2$ teff $\left._{\mathrm{TC}}=1 \cdot 266 \mathrm{l} / \mathrm{s}\right)$. 